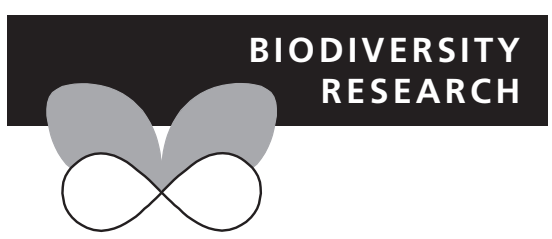

\title{
Spatial and temporal variation in population trends in a long-distance migratory bird
}

Catriona A. Morrison ${ }^{1 \star}$, Robert A. Robinson ${ }^{2}$, Jacquie A. Clark ${ }^{2}$ and Jennifer A. Gill ${ }^{1}$

${ }^{1}$ School of Biological Sciences, University of East Anglia, Norwich NR4 7TJ, UK, ${ }^{2}$ British Trust for Ornithology, The Nunnery, Thetford IP24 2PU, UK

${ }^{*}$ Correspondence: Catriona A. Morrison, School of Biological Sciences, University of East Anglia, Norwich NR4 7TJ, UK. E-mail: c.morrison@uea.ac.uk

\begin{abstract}
Aim Over the past three decades, evidence has been growing that many AfroPalaearctic migratory bird populations have suffered sustained and severe declines. As causes of these declines exist across both the breeding and nonbreeding season, identifying potential drivers of population change is complex. In order to explore the roles of changes in regional and local environmental conditions on population change, we examine spatial and temporal variation in population trajectories of one of Europe's most abundant Afro-Palaearctic summer migrants, the willow warbler, Phylloscopus trochilus.
\end{abstract}

Location Britain and Ireland.

Methods We use national survey data from Britain and Ireland (BBS: BTO/ RSPB/JNCC Breeding Bird Survey and CBS: BWI/NPWS/Heritage Council Countryside Breeding Survey) from 1994 to 2006 to model the spatial and temporal variation in willow warbler population trends.

Results Across Britain and Ireland, population trends follow a gradient from sharp declines in the south and east of England to shallow declines and/or slight increases in parts of north and west England, across Scotland and Ireland. Decreasing the spatial scale of analysis reveals variation in both the rate and spatial extent of population change within central England and the majority of Scotland. The rates of population change also vary temporally; declines in the south of England are shallower now than at the start of the time series, whereas populations further north in Britain have undergone periods of increase and decline.

Main conclusion These patterns suggest that regional-scale drivers, such as changing climatic conditions, and local-scale processes, such as habitat change, are interacting to produce spatially variable population trends. We discuss the potential mechanisms underlying these interactions and the challenges in addressing such changes at scales relevant to migratory species.

\section{Keywords}

Habitat change, migratory connectivity, population dynamics, sub-Saharan Africa, willow warbler.

\section{INTRODUCTION}

Across Europe, population declines are currently being reported in a wide range of Afro-Palaearctic bird species (Burfield \& van Bommel, 2004; Møller et al., 2008). While the causes of these declines are not yet fully understood, the impact appears to be greater in long-distance (particularly sub-
Saharan) than short-distance migrants (Sanderson et al., 2006; Hewson \& Noble, 2009). Consequently, attention has focussed on changes occurring on winter and passage sites or in timing of migration, including changing patterns of rainfall over the Sahel (Møller, 1989; Peach et al., 1991; Szep, 1995; Robinson et al., 2003) and the loss and degradation of key winter habitats through expansion of human populations 
(Newton, 2008). However, recent changes in breeding numbers and fecundity of migratory species have also been linked to habitat changes on breeding areas (Browne \& Aebischer, 2001) and larger-scale factors such as climate change (Both \& Visser, 2001; Huppop \& Huppop, 2003). Identifying the causes of population change in migratory birds is thus likely to require an unravelling of the effects and the relative importance of local- and regional-scale processes and the potentially complex manner in which they may interact (Mustin et al., 2007).

In general, regional-scale processes operating in the breeding season, such as large-scale variation in climatic conditions, may be expected to lead to large-scale spatial gradients of population change, whereas local-scale environmental processes, such as habitat change, may tend to create spatially variable population trends. Local-scale changes operating in regional synchrony (e.g. the spread of a new pathogen or predator) could also result in a large-scale spatial gradient of population change. In migratory birds, however, connectivity between breeding grounds and wintering grounds can potentially result in drivers in one season influencing population trends in another season (Marra et al., 1998; Gill et al., 2001; Gunnarsson et al., 2005). When migratory connectivity is strong, such that individuals from different breeding locations also winter in geographically distinct areas, changes within the wintering grounds have the potential to result in large-scale spatial gradients of population change in the breeding grounds. However, when there is weak or no migratory connectivity, non-breeding season environmental changes could result in small-scale variation in breeding season population trends, for example as reduced survival on passage or in winter results in fewer birds returning across the breeding range. The extent to which conditions in the non-breeding season influence population trends will also depend on their interaction with processes operating during the breeding season. Synergistic interactions (e.g. through individuals experiencing either the best or the worst conditions in both seasons, termed seasonal matching by Gunnarsson et al., 2005), could exacerbate population declines, while opposing interactions (individuals experiencing good conditions in one season and poor conditions in the other) could buffer population declines. Exploring patterns of spatial variation in population trends can therefore highlight the most likely sources of environmental changes driving these patterns.

One long-distance Afro-Palaearctic migrant, the willow warbler (Phylloscopus trochilus), provides an opportunity to explore many of these issues. The willow warbler is one of Europe's most abundant summer migrants, with population levels estimated at more than 56 million pairs (Burfield \& van Bommel, 2004), of which the UK population comprises 2.6 million pairs (Newson \& Noble, 2008). From late-March to mid-July, willow warblers are on their breeding grounds throughout Europe, most frequently in scrub and woodland (Cramp, 1992). Willow warblers depart from their breeding grounds in the latter part of the summer to arrive in Africa in late August and September. Within Africa, willow warblers tend to stay in the Sahel-Sudan zone, just south of the Sahara desert, for 1-2 months before travelling further south in late October or November (Salewski et al., 2002; Newton, 2008). The limited evidence available from reports of ringed birds suggests that British-breeding willow warblers winter in the Gulf of Guinea, principally around the Ivory Coast and Ghana (Norman \& Norman, 2002). Evidence of geographic variation in population trends of breeding willow warblers first became apparent in the 1990s, when numbers in farmland and woodland Common Bird Census (CBC) plots in Britain suggested a decline in southern Britain which appeared to coincide with declining survival rates (Peach et al., 1995). By contrast, no evidence for any changes in population size or survival in the north of Britain was apparent at that time.

Since 1994 in the UK and 1998 in the Republic of Ireland, willow warbler abundance has been monitored as part of the British Trust for Ornithology (BTO)/Royal Society for Protection of birds (RSPB)/Joint Nature Conservation Committee (JNCC) Breeding Bird Survey (BBS) and the Bird Watch Ireland (BWI)/National Parks and Wildlife Service (NPWS)/ Heritage Council Countryside Bird Survey (CBS), respectively (Coombes et al., 2006 and Risely et al., 2009). We use these large-scale datasets to present a comprehensive account of (1) large-and small-scale spatial variation in willow warbler population trends in Britain and Ireland over the last 13 years, (2) the extent to which these spatial trends vary across different time periods. We discuss these findings in the context of the variety of ecological drivers and interactions which may underlie the observed patterns.

\section{METHODS}

\section{Data collection}

An index of the abundance of widespread bird species has been provided by the BBS since 1994 and by the CBS since 1998. In the BBS, $1 \mathrm{~km}^{2}$ survey sites are allocated to volunteers following a stratified random sampling procedure and coverage is representative of habitats throughout the UK. Within each of 83 regions (roughly equating to UK counties), the number of BBS sites reflects the number of potential volunteers in the region while the location of sites is selected at random. Between 1994 and 2006, the BBS covered an average of 2178 sites each year, ranging from 1569 in 1994 to 3287 in 2006, providing comprehensive coverage of the majority of Britain \& Northern Ireland. Coverage is greatest in lowland areas and in the south-east of England and lower in the north of Scotland. Consequently, confidence in population trends estimated across the Highlands and Islands of Scotland, where fewer sampling points are available, is likely to be lower than in areas of greater coverage. Overall, willow warblers were detected in 2400 BBS squares over this time period (Fig. 1).

In the CBS, the Republic of Ireland is divided into eight regions within which $10 \mathrm{~km}$ squares are randomly selected and allocated to volunteers in sequence. In order to ensure sufficient spatial coverage, the $1 \mathrm{~km}$ square at the extreme south-west corner of each $10 \mathrm{~km}$ of square is surveyed. 


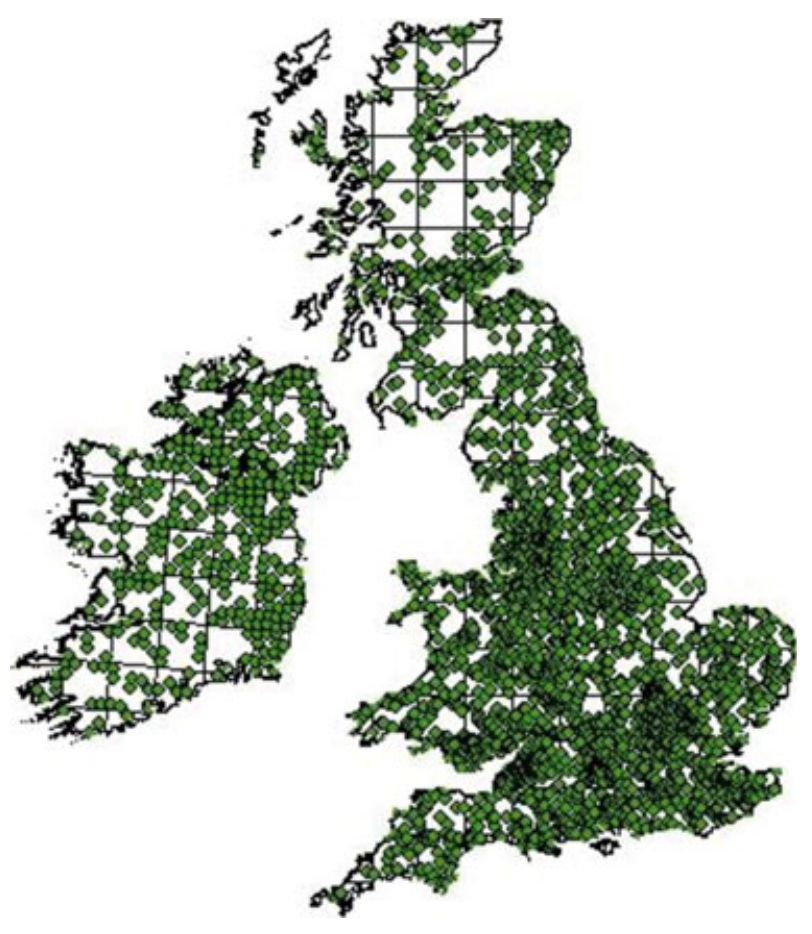

Figure 1 The distribution of all Breeding Bird Survey and Countryside Bird Survey sites in which willow warblers were recorded between 1994 and 2006, with the $50 \mathrm{~km}$ grid overlain.

Between 1998 and 2006, an average of 300 sites was surveyed each year, with coverage being greatest in the north and east of the country and less frequent in the south-west. Overall, willow warblers were detected in 328 CBS squares over this time period (Fig. 1).

BBS and CBS use very similar methodologies. Each $1 \mathrm{~km}$ square is visited three times a year. In the first visit, two parallel $1-\mathrm{km}$ transects lines are chosen and the habitats of each 200-m section along both transects are recorded using an hierarchical coding system (Crick, 1992). Two subsequent early morning visits to the square are then carried out, a minimum of 4 weeks apart; the first between early-April and mid-May and the second between mid-May and late-June. Transect counts typically start between 6 and 7 AM, and bird count visits last around $90 \mathrm{~min}$; days with poor weather are avoided as this can influence the number of birds recorded. Observers record all birds seen or heard within $100 \mathrm{~m}$ of the transect line, excluding birds that can be identified as juveniles, separately for each 200-m transect section.

\section{Estimation of population trends}

Using the maximum of the two counts (early- and latebreeding season), the total number of willow warblers detected across all transect sections within each $1 \mathrm{~km}$ square was calculated for each year. In addition, the majority habitat of each survey square was defined as the most frequent primary habitat across all transect sections within each square. Habitats were grouped into one of six broad categories; grass, mixed, scrub, human, wood and wetland (see Crick 1992 for details of habitats).

In order to examine the variation in willow warbler abundance over time across Britain \& Ireland, survey data were aggregated over $50 \mathrm{~km}$ grid squares and a Poisson general linear model with a log link was fitted in SAS 9.1 (SAS Institute Inc., Cary, NC, USA). To explore the influence of spatial scale on this variation, counts were summed over three spatial scales $\left(100,50\right.$ and $\left.10 \mathrm{~km}^{2}\right)$. While patterns of population trends at the larger spatial scales (100 and $50 \mathrm{~km}^{2}$ ) may indicate broad regional shifts in population trajectories, aggregating the data at these scales may also mask important and informative local variability in population trends. In particular, large-scale patterns within areas where data are sparse or not available may be heavily influenced by trends in surrounding squares. The survey data were therefore also aggregated within $10 \mathrm{~km}$ grid squares. In order to explore the effect of the location of the boundaries of data aggregation on estimated population trends, we carried out an additional analysis at the $50 \mathrm{~km}$ scale with the $50 \mathrm{~km}$ grid offset by $25 \mathrm{~km}$ both latitudinally and longitudinally.

At each scale, Poisson general linear mixed models with a log link were fitted to describe changes in abundance over time. Counts were modelled as a function of year $\times$ site, with site as a random effect nested within habitat type. This allowed sites with the same habitat types to be treated as more similar by the model, thus accounting for some of the variation introduced by habitat differences. The model was also offset by the number of squares in each spatial unit per year to account for differences in survey effort. Squares with fewer than two observations were excluded from all analyses. For the 100 and $50 \mathrm{~km}$ analyses, all squares encompassing fewer than five BBS or CBS sites were removed, as these were unlikely to cover enough of the square to give a true representation of population trend over the whole area.

Using these predicted rates of change for survey squares at all three spatial levels, kriging was then applied to produce smoothed prediction surfaces of annual population change across the whole of Britain \& Ireland. Suitability of this technique for use with BBS data is discussed in Newson \& Noble (2008). To explore temporal variation in these spatial patterns, the trends were calculated for three equal time periods (1994-97, 1998-2001, 2002-06) at the $50 \mathrm{~km}$ scale.

\section{RESULTS}

The direction and magnitude of abundance trends varies greatly with geographical location (Table 1). Across Britain \& Ireland, there was significant latitudinal and longitudinal variation in population trends, from negative trends in the south and east to more positive trends in the north and west. There was also a significant interaction between latitude and longitude, indicating that populations in the east of the country are declining faster than average for their latitude, while trends in the west tend to be higher than average for their latitude (Table 1). 
Table 1 Parameter estimates from a general linear model of variation in willow warbler population trends in Britain and Ireland between 1994 and 2006, in relation to latitude and longitude of the $15,750 \mathrm{~km}^{2}$ containing BBS and CBS data (see Fig. 1 for distribution of squares). Also given are the Wald $\chi^{2}$ values and associated significance values for each term.

\begin{tabular}{lrrr}
\hline Variable & Estimate (SE) & \multicolumn{1}{l}{$\chi^{2}$} & $P$ \\
\hline Latitude & $0.020(0.006)$ & 11.29 & 0.0008 \\
Longitude & $-0.227(0.074)$ & 9.46 & 0.0021 \\
Latitude $\times$ longitude & $0.004(0.001)$ & 8.48 & 0.0036 \\
\hline
\end{tabular}

BBS, Breeding Bird Survey; CBS, Countryside Bird Survey.

The spatial variation in population trends at the $100 \mathrm{~km}$ scale highlights the broad patterns of latitudinal and longitudinal variation in abundance trends, with both north/south and east/west gradients of population change apparent (Fig. 2). The greatest declines in willow warbler abundance have occurred in the south-east of England, from which a gradient of population change is apparent in zones running from the south-east to the north-west throughout England, Wales and into Scotland. A zone in which willow warblers have slightly increased in number is apparent in the north-west of Scotland. Slight population increases are also apparent across the majority of the Republic of Ireland at the $100 \mathrm{~km}$ scale (Fig. 2a). When the trends are aggregated within $50 \mathrm{~km}$ grid squares, trends throughout much of Ireland, England and southern Scotland are similar to the $100 \mathrm{~km}$ scale, but zones of apparent increase in Wales and north-west England are indicated, and the location of the increasing populations in Scotland appears to be more easterly (Fig. 2b). When the $50 \mathrm{~km}$ grid was offset by $25 \mathrm{~km}$ latitudinally and longitudinally, population trends were found to be consistent in areas with high coverage (e.g. south-east England) and there were only slight changes in the estimated population trends in areas with lower coverage (e.g. north-west Scotland).
At the $10 \mathrm{~km}$ scale, more spatial variability is apparent but, across the majority of England, the overall pattern of widespread declines is consistent with the larger scales (Fig. 2c). In both Scotland and Ireland, however, aggregating the data at the $10 \mathrm{~km}$ scale suggests the presence of local patches of declines and increases. In Scotland, patches of decline in the far-north coincide with areas of relatively sparse data (Fig. 1) which may cause over-estimation of the true spatial extent of these declines.

The patterns of spatial variation in willow warbler population trends across the UK have not been consistent throughout the 13 years over which they have been recorded by the BBS. In the south and east of England, populations experienced slight declines from 1994 to 1997, followed by sharp declines in 1998-2001 and relative stability in 2002-06, with patches of both slight declines and increases across the region (Fig. 3). These trends represent a decline from already relatively small population sizes below $54^{\circ} \mathrm{N}$ at the start of the survey period to extremely low numbers which, from 2001 onwards, fluctuate around 1.0-1.2 willow warblers per $1 \mathrm{~km}^{2}$ survey plot (Fig. 4). Above $54^{\circ} \mathrm{N}$, willow warbler abundance is higher (Fig. 4). In central England and southern Scotland, from $54^{\circ}$ to $56^{\circ} \mathrm{N}$, population trends are similar across all temporal periods with widespread slight increases in abundance across the region (Figs $3 \& 4$ ). Above $56^{\circ} \mathrm{N}$, willow warbler abundance is high (Fig. 4) and there were increases across much of the region from 1994 to 1997 (Fig. 3). As in the south of England, this is by followed a period of decline from 1998 to 2001, with areas of modest increase and decrease apparent from 2002 to 2006 (Fig. 3). This stability is, however, at a much higher level of abundance than in the south (Fig. 4).

\section{Impact of distribution of habitat types on population trends}

An array of habitat types were covered by the BBS squares that contained willow warblers. However, throughout Britain \&

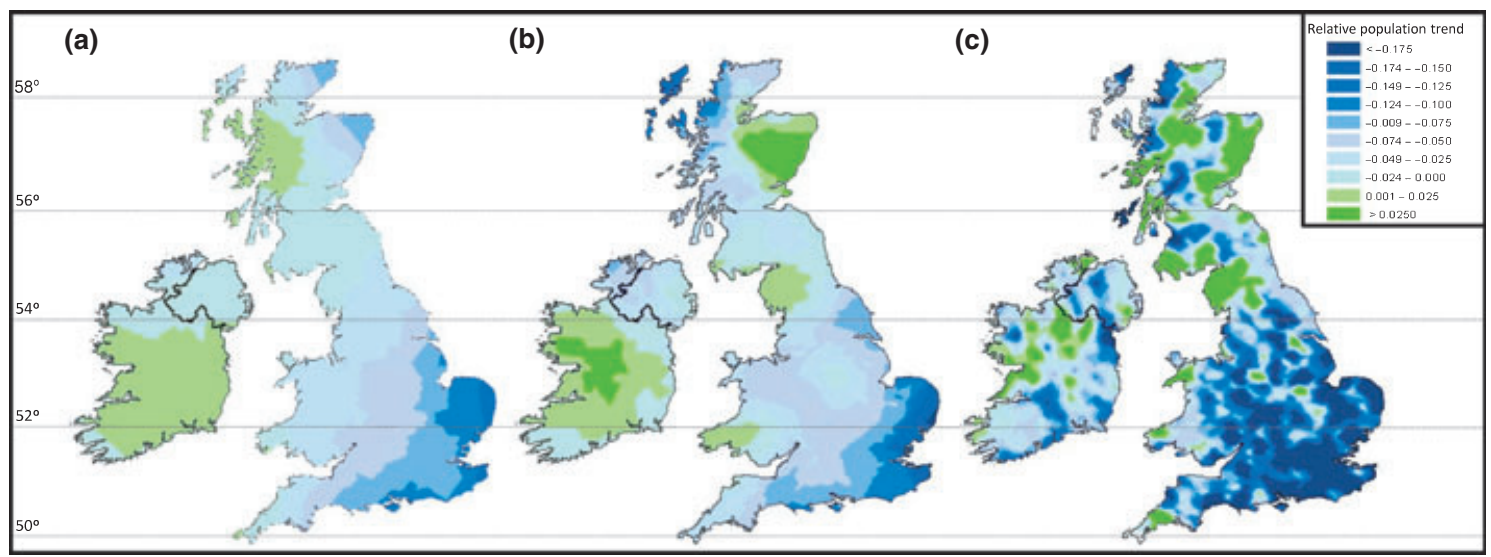

Figure 2 Spatial variation in the relative change in number of British and Irish willow warblers in $1 \mathrm{~km}^{2}$ Breeding Bird Survey and Countryside Bird Survey survey plots between 1994 and 2006 (UK) and 1998 and 2006 (Republic of Ireland) aggregated at (a) 100 km² (b) $50 \mathrm{~km}^{2}$ (c) $10 \mathrm{~km}^{2}$. 


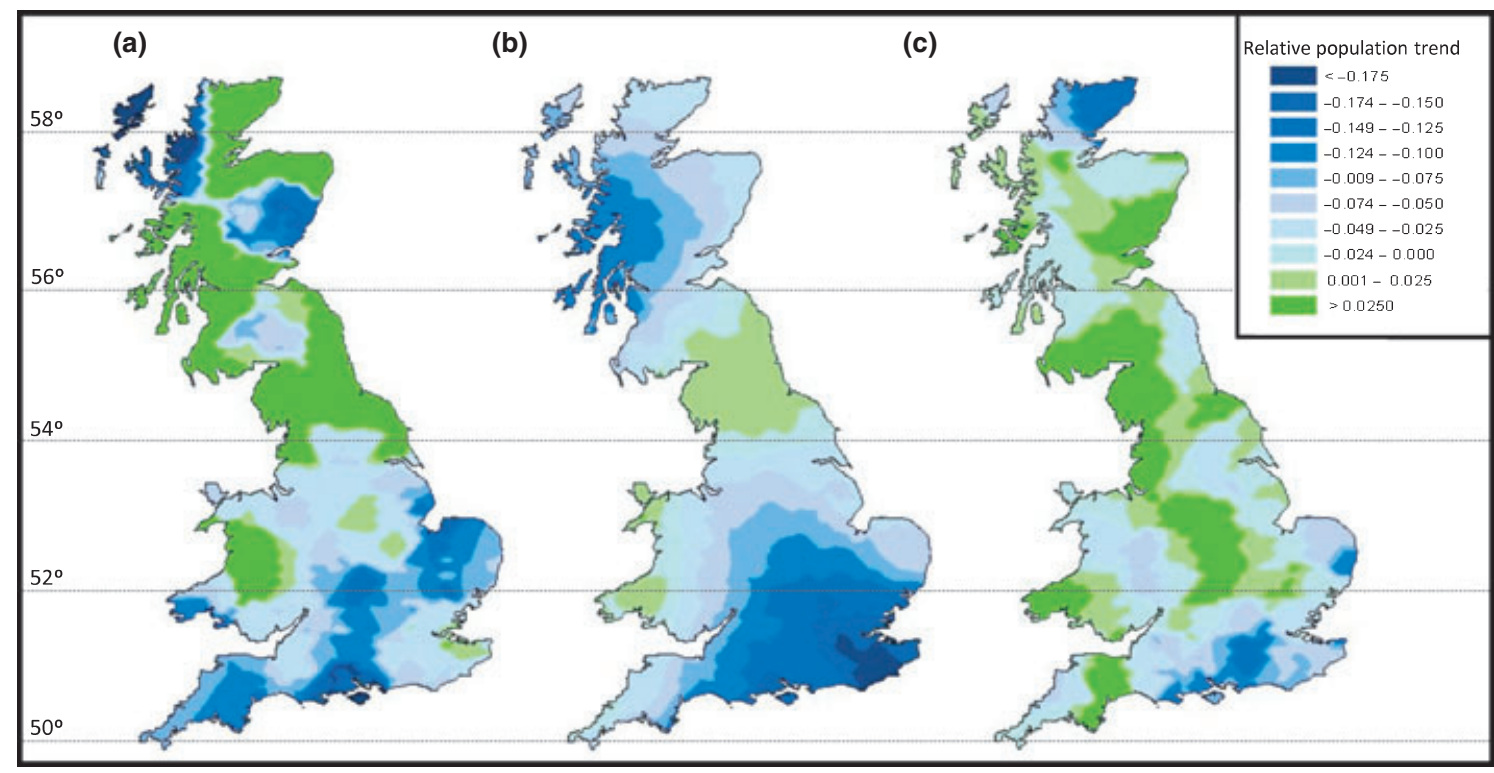

Figure 3 Spatial variation in the relative change in number of UK willow warblers in 1 km$^{2}$ Breeding Bird Survey sites between (a) 1994-97 (b) 1998-2001 (c) 2002-06. Data are aggregated to the $50 \mathrm{~km}$ scale.

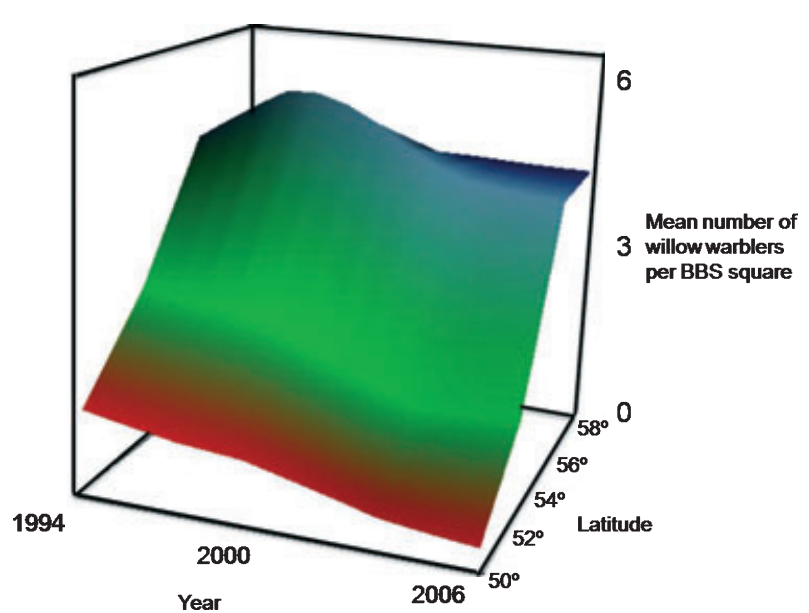

Figure 4 Latitudinal variation in the number of willow warblers per $1 \mathrm{~km}^{2}$ in Britain between 1994 and 2006.

Ireland, the coverage of different habitat types is relatively even, with c. $70-90 \%$ of all squares containing willow warblers comprising grass, which encompasses all semi-natural grasslands and marsh habitats. It is therefore unlikely that patterns of population change are a result of uneven habitat distribution within the BBS and CBS, though this does not mean that the population trends are not influenced by changes in habitat quality or availability.

\section{DISCUSSION}

Willow warbler population trends are highly spatially variable across Britain \& Ireland, with the sharp declines in the south and east of England, gradually increasing to shallow declines and slight increases in areas of north and west England, Scotland and Ireland. In addition to this large-scale gradient, there are also patches of small-scale variation in areas of central England and much of Scotland. While declines in the south-east of England have been continuous throughout the survey period, reducing the population from $\sim 1.94$ ( $\pm 0.09 \mathrm{SE}$ ) to $\sim 1.2( \pm 0.04 \mathrm{SE})$ willow warblers per $1 \mathrm{~km}$ survey square, populations in the north of Britain have experienced periods of both increase and decrease in abundance, with abundance now estimated at $\sim 4.6( \pm 0.24 \mathrm{SE})$ willow warblers per $1 \mathrm{~km}$ survey square. The extent of spatial variation in population trends and their consistency across different spatial scales help to highlight possible drivers of population change and suggest an influence of both regional-scale drivers, such as changing climatic conditions, and local-scale processes, such as habitat change.

\section{Comparisons of spatial and temporal scales of measurement}

In the south of England, BBS coverage is high and widespread declines in the populations of willow warblers are evident across the region at all three spatial scales (100, 50 and $10 \mathrm{~km})$. Willow warbler populations in the south of England have been declining since the mid 1980s (Peach et al., 1995), thus the BBS survey captures the end of a sustained and widespread period of decline across this region, with many areas being reduced to one or fewer willow warbler pairs per $\mathrm{km}^{2}$. In the south-east of England, the rate of population change is also consistent across spatial scales, which suggests the influence of either a regionalscale environmental driver or local-scale drivers occurring synchronously throughout the region. However, population abundance in these areas is now so low that detecting 
population responses to current drivers could prove difficult. By contrast, from central England northwards through Scotland and Ireland, the maximum rate of decline increases with decreasing spatial scale, which may suggest that the influences of local-scale drivers of change are masked at the larger spatial scales by less-severe changes in neighbouring squares. However, in the far north and west of both Britain \& Ireland, inconsistencies between the three spatial scales (100, 50 and $10 \mathrm{~km}$ ) may also reflect data limitations. The smaller number of survey points in these areas can result in the precise location of the boundaries of data aggregation exerting a strong influence on the spatial patterns. Thus, while zones of population increase in the north and west of Britain \& Ireland were clearly present during this time period, the boundaries of these zones of increase are not clear.

\section{Potential drivers of spatial variation in population trends}

The clear large-scale spatial gradient in willow warbler population trends may suggest the involvement of regionalscale drivers operating within the breeding season, such as regional-scale spatial variation in changes in mean spring temperatures and the seasonality of rainfall. Mean spring temperatures in the south and east of Britain are increasing faster than in the north and west (Perry, 2006). Such advancement of spring temperatures has been directly linked to advancements in the period of peak insect abundance (Visser \& Both, 2005; Both et al., 2006). As well as rising spring temperatures, some areas in the south of the UK are also experiencing a greater volume of rainfall over shorter time periods (Perry, 2006). High levels of rainfall can influence the ability of birds to provide food for chicks (Keller \& van Nordwijk, 1994). Thus, in the south of the UK, rising temperatures may increase the likelihood of mismatches with key resources and increasing rainfall may reduce the success of breeding attempts. By contrast, in the north and west of Britain \& Ireland the increases in rainfall have primarily occurred during winter months (Perry, 2006) and therefore the risk of rainfall increasing nest failure rates may be lower.

Regional-scale variation in breeding season population trends could also result from local-scale changes that are occurring throughout these regions (2c). For example, increases in the abundance and range of roe (Capreolus capreolus) and muntjac (Muntiacus reevesi) deer in the southeast of England (Ward, 2005; Corbet \& Harris, 2008) have been linked directly to the loss of woodland understorey and declines of breeding songbirds (Gill \& Fuller, 2007). Although this habitat loss operates at a small scale, the rapid range expansion of muntjac, in particular, may mean that these changes are occurring in synchrony across large areas, and could thus cause the type of large-scale population gradient observed in willow warbler breeding trends. Conversely, in the British uplands, there is potential for recent changes in management practices to actively promote extensive scrub and woodland regeneration (Gillings et al., 1998, 2000). The rate and extent of this regeneration is, however, likely to be limited, restricting its benefit to localized patches. This is therefore an example of a process likely to result in high levels of local variation in population trends such as those observed in the north and west of Britain \& Ireland.

The spatial structure of population trends in the breeding season can also be greatly impacted by processes occurring during the non-breeding season, depending on the extent of migratory connectivity. On the wintering grounds in Africa, willow warblers are relatively mobile and exploit a wide range of habitats (Norman \& Norman, 2002; Salewski \& Jones, 2006; Newton, 2008), suggesting that any migratory connectivity between the locations of breeding grounds and wintering grounds is likely to be relatively weak. In Africa, the effects of the recent increase in the frequency of drought conditions in the Sahel region on migrant species have been exacerbated by the substantial ecological impacts of increasing human populations and associated farming practices (Hein, 2006; Hein \& de Ridder, 2006). Overgrazing causes reductions in the quality of grasslands, removal of trees and shrubs and the loss and degradation of wetlands which, coupled with the increasing use of pesticides on farmlands (Mullie \& Keith, 1993), has limited the availability of passage areas and the food resources of long-distance migrants (Newton, 2008). In systems without strong migratory connectivity, this type of widespread habitat degradation would be expected to result in a high level of local variation in breeding season population trends, but not a large-scale spatial gradient in trends. However, if willow warblers from the north of Britain \& Ireland tend to either migrate at different times, use different passage sites or use the same sites for differing periods of time, or winter in different areas than those from the south of England, environmental changes in Africa could lead to the regional-scale variation in breeding season population trends.

\section{CONCLUSION}

The regional-scale gradient in breeding season population trends of willow warblers in Britain \& Ireland suggests regional-scale drivers, such as changing climatic conditions, across different parts of Britain \& Ireland. However, if there is migratory connectivity or variation in the timing of passage of birds from different parts of Britain \& Ireland, then regionalscale environmental changes in Africa could also be creating these patterns. In addition, the high level of local-scale variation in the north and west suggests a potential interaction between regional-scale drivers and spatially fragmented localscale drivers, although relatively low coverage in this part of the UK could also influence these patterns. Thus, unravelling the drivers requires the quantification of levels of migratory connectivity and differences in the timing of migration, and identification of the extent to which local-scale habitat change and regional-scale climatic change overlap with the spatial distribution of population change. 


\section{ACKNOWLEDGEMENTS}

The BBS is organized by the British Trust for Ornithology and jointly funded by the British Trust for Ornithology, Royal Society for the Protection of Birds and the Joint Nature Conservation Committee (on behalf of the Council for Nature Conservation and the Countryside, the Countryside Council for Wales, Natural England and Scottish Natural Heritage). The CBS is a joint project of BirdWatch Ireland, the National Parks and Wildlife Service and the Heritage Council. It is coordinated by Dick Coombes (BirdWatch Ireland) and the Steering Group includes Alyn Walsh \& David Tierney (NPWS), Liam Lysaght (National Biodiversity Data Centre), Cliona O’Brien (Heritage Council), Prof. John O'Halloran (University College Cork), Dick Coombes, Olivia Crowe \& Alan Lauder (BirdWatch Ireland). We thank all the volunteers and regional organizers of both surveys for their continued effort and support. We thank Olivia Crowe, Stuart Newson, David Noble, Kate Risely for their help with data extraction and analysis. This study forms part of a NERC Research Case studentship in partnership with the BTO.

\section{REFERENCES}

Both, C. \& Visser, M.E. (2001) Adjustment to climate change is constrained by arrival date in a long-distance migrant bird. Nature, 411, 296-298.

Both, C., Bouwhuis, S., Lessells, C.M. \& Visser, M.E. (2006) Climate change and population declines in a long-distance migratory bird. Nature, 441, 81-83.

Browne, S.J. \& Aebischer, N.J. (2001). The Role of agricultural intensification in the decline of the turtle Dove Streptopelia Turtur. English Nature Research Report 421. English Nature, Peterborough.

Burfield, I.J. \& van Bommel, F.P.J. (2004) Birds in Europe: population estimates, trends and conservation status. Bird Life International, Cambridge.

Coombes, R.H., Crowe, O., Lysaght, L., O’Halloran, J., O'Sullivan, O. \& Wilson, J.H. (2006) Countryside bird survey 1998-2000. BirdWatch Ireland, Dublin.

Corbet, G.B. \& Harris, S. (2008) The handbook of British mammals. Blackwell Scientific Publications, Oxford.

Cramp, S. (ed.) (1992). Handbook of the birds of Europe, the Middle East and Northern Africa, Vol. VI. Oxford University Press, Oxford.

Crick, H.Q.P. (1992) A bird-habitat coding system for use in Britain and Ireland incorporating aspects of land-management and human activity. Bird Study, 39, 1-12.

Gill, R.M.A. \& Fuller, R.J. (2007) The effects of deer browsing on woodland structure and songbirds in lowland Britain. Ibis, 149, 119-127.

Gill, J.A., Norris, K., Potts, P.M., Gunnarsson, T.G., Atkinson, P.W. \& Sutherland, W.J. (2001) The buffer effect and largescale population regulation in migratory birds. Nature, 412, 436-438.
Gillings, S., Fuller, R.J. \& Henderson, A.C.B. (1998) Avian community composition and patterns of bird distribution within birch-heath mosaics in north-east Scotland. Ornis Fennica, 75, 27-37.

Gillings, S., Fuller, R.J. \& Balmer, D.E. (2000) Breeding birds in scrub in the Scottish highlands: variation in community composition between scrub type and successional stage. Scottish Forestry, 54, 73-85.

Gunnarsson, T.G., Gill, J.A., Newton, J., Potts, P.M. \& Sutherland, W.J. (2005) Seasonal matching of habitat quality and fitness in a migratory bird. Proceedings of the Royal Society B: Biological Sciences, 272, 2319-2323.

Hein, L. (2006) The impacts of grazing and rainfall variability on the dynamics of a Sahelian rangeland. Journal of Arid Environments, 64, 488-504.

Hein, L. \& de Ridder, N. (2006) Desertification in the Sahel: a reinterpretation. Global Change Biology, 12, 751-758.

Hewson, C.M. \& Noble, D.G. (2009) Population trends of breeding birds in British woodlands over a 32-year period: relationships with food, habitat use and migratory behaviour. Ibis, 151, 464-486.

Huppop, O. \& Huppop, K. (2003) North Atlantic oscillation and timing of spring migration in birds. Proceedings of the Royal Society B: Biological Sciences, 270, 233-240.

Keller, L.F. \& van Nordwijk, A.J. (1994) Effects of local environmental conditions on nestling growth in the great tit Parus major L. Ardea, 82, 349-362.

Marra, P. P., Hobson, K. A. \& Holmes, R. T. (1998) Linking winter and summer events in a migratory bird by using stable-carbon isotopes. Science, 282, 1884-1886.

Møller, A.P. (1989) Population-dynamics of a declining swallow, Hirundo-rustica population. Journal of Animal Ecology, 58, 1051-1063.

Møller, A.P., Rubolini, D. \& Lehikoinen, E. (2008) Populations of migratory bird species that did not show a phenological response to climate change are declining. Proceedings of the National Academy of Sciences USA, 105, 16195-16200.

Mullie, W.C. \& Keith, J.O. (1993) The effects of aerially applied fenitrothion and chlorpyrifos on birds in the savanna of northern Senegal. Journal of Applied Ecology, 30, 536-550.

Mustin, K., Sutherland, W.J. \& Gill, J.A. (2007) The complexity of predicting climate-induced ecological impacts. Climate Research, 35, 165-175.

Newson, S.E. \& Noble, D. (2008) The Breeding Bird Survey for mapping Britain's birds: a preliminary assessment of performance at two spatial scales. Rivista Catalana d'Ornithologia, 24, 107-117.

Newton, I. (2008) The migration ecology of birds. Academic Press, London.

Norman, W. \& Norman, S.C. (2002) Willow warbler (Phylloscopus trochilus) the migration atlas: movements of the birds of Britain and Ireland (ed. by C.V. Wernham, M.P. Toms, J.H. Marchant, J.A. Clark, G.M. Siriwardena and S.R. Baillie). T \& A.D. Poyser, London. 
Peach, W., Baillie, S. \& Underhill, L. (1991) Survival of British sedge warblers, Acrocephalus schoenobaenus, in relation to West African rainfall. Ibis, 133, 300-305.

Peach, W.J., Crick, H.Q.P. \& Marchant, J.H. (1995) The demography of the decline in the British willow warbler population. Journal of Applied Statistics, 22, 905-922.

Perry, M. (2006) A spatial analysis of trends in the UK climate since 1914 using gridded datasets. Climate Memorandum No 21. (ed. by N. C. I. Centre).

Risely, K., Noble, D.G. \& Baillie, S.R. (2009) The Breeding Bird Survey 2008, BTO Research Report 537. British Trust for Ornithology, Thetford.

Robinson, R.A., Crick, H.Q.P. \& Peach, W.J. (2003) Population trends of Swallows Hirundo rustica breeding in Britain. Bird Study, 50, 1-7.

Salewski, V. \& Jones, P. (2006) Palearctic passerines in Afrotropical environments: a review. Journal of Ornithology, 147, 192-201.

Salewski, V., Bairlein, F. \& Leisler, B. (2002) Different wintering strategies of two Palearctic migrants in West Africa - a consequence of foraging strategies? Ibis, 144, 85-93.

Sanderson, F.J., Donald, P.F., Pain, D.J., Burfield, I.J. \& van Bommel, F.P.J. (2006) Long-term population declines in Afro-Palearctic migrant birds. Biological Conservation, 131, 93-105.

Szep, T. (1995) Relationship between West-Africa rainfall and the survival of central-European sand martins, Riparia riparia. Ibis, 137, 162-168.

Visser, M.E. \& Both, C. (2005) Shifts in phenology due to global climate change: the need for a yardstick. Proceedings of the Royal Society B: Biological Sciences, 272, 2561-2569.

Ward, A.I. (2005) Expanding ranges of wild and feral deer in Great Britain. Mammal Review, 35, 165-173.

\section{BIOSKETCHES}

Catriona Morrison is a $\mathrm{PhD}$ student at the University of East Anglia, funded by NERC with the British Trust for Ornithology (BTO) as CASE partner. Her PhD uses long-term BTO datasets to explore the relative impact of demographic and environmental factors on population changes in a longdistance migratory bird.

Rob Robinson is a Principal Ecologist at the British Trust for Ornithology (BTO) and chair of the BTO Population Dynamics and Modelling Theme Group. His main interests lie in understanding how changes in bird populations and distributions are determined by demography, particularly the combination of survival and productivity.

Jacquie Clark is the head of Demography at the British Trust for Ornithology (BTO) and joint chair of the BTO Migration and Ecology of Migrants Theme Group. In addition to migration, her main research interests are the control of mass in birds, particularly in cold weather and in relation to the predation/starvation trade-off.

Jennifer Gill is a Reader at the University of East Anglia, Norwich. Her primary research interests are in the ecology and evolution of migratory systems, and in applied issues such as the impacts of climate change, sea level rise and environmental change on biodiversity in coastal zones.

Author contributions: all authors conceived the study; C.M. carried out the research and analysed the data; all authors contributed to the writing of the paper.

Editor: Mark Robertson 